\title{
Variable Phenotypic Presentation of Primary Immunodeficiency Diseases: A Challenge for Diagnosis
}

\section{Hamoud Al-Mousa*}

Pediatric Allergy and Clinical Immunology, King Faisal Specialist Hospital and Research Centre, College of Medicine, Alfaisal University, Riyadh, Saudi Arabia

\section{Introduction}

Primary Immunodeficiency Diseases (PIDs) are a heterogeneous group of disorders that affect the development or the function of the immune system mostly presenting as severe recurrent infections with an increased incidence of autoimmunity and malignancies. The spectrum of such diseases has grown during the past 50 years, with currently more than 180 different syndromes having been described [1]. In most cases PIDs are monogenic disorders that follow a simple Mendelian inheritance. Some PIDs are particularly common in certain geographical areas because of founder effects, restricted genetic isolates or higher consanguinity rates. Despite major advances over the last 20 years in the molecular characterization of PIDs, many patients still go undiagnosed or are diagnosed late, with adverse clinical consequences and are faced with lifelong disability.

Most of the classical PIDs were identified by their clinical and immunologic presentations and confirmed at their molecular level. However, several immune system gene mutations had variable phenotypic presentations making a firm diagnosis by clinical and immunologic criteria problematic. For example, mutations in Recombinase Activating Gene 1 (RAG1) were found to cause Severe Combined Immunodeficiency Disease (SCID) [2], while hypomorphic mutations in the same gene present with omen syndrome phenotype [3]. It was then found that identical mutations in this gene could cause either syndromes [4] and to make it more complicated hypomorphic mutation in the same gene can present with Oligoclonal $\gamma / \delta \mathrm{T}$ cells, autoimmune disease, and CMV infection [5]. Thus, it is possible that environmental or other genetic factors modify the clinical manifestation of such mutations. Several other genes mutations of the immune system result in variable phenotypes. Mutations in Bruton's tyrosine kinase gene (Btk) result into $\mathrm{x}$-linked agammaglobulinemia [6] or polysaccharide antibody deficiency [7]. Mutations in the WASP gene result in Wiskott-Aldrich syndrome but also in X-linked thrombocytopenia [8]. SH2D1A mutations have been shown to cause variously fatal infectious mononucleosis, common variable immunodeficiency [9], or hemophagocytic lymphohistiocytosis [10].

Clinical ambiguity also arises from the fact that identical clinical syndromes can be caused by mutations in different immune system genes. SCID can be caused by at least 14 different genes [11] and more ever Omenn syndrome can be caused by different hypomorphic mutations in SCID causing genes [12]. In addition Hyper IgM syndrome can be caused by mutation in 6 different genes [13]. These variable phenotypic and molecular characterizations of PIDs pose a significant challenge to the approach and the diagnosis mostly related to lack of knowledge, appropriate immunological and molecular assays or the need to screen for several genes.

Several PIDs regional registries already exist in a number of countries. These patient registries have already and will continue to shed light on the pathology and natural history of these varied disorders. Merging these regional registries into larger international databases will help to create a large pool of patient data and the establishment of disease specific database registries will expand our knowledge on variable clinical presentation, management and outcome of the targeted diseases.

Assessment of T Cell Receptor Excision Circles (TRECs) using dried blood spots collected at birth is being used recently for newborn screening of Severe Combined Immunodeficiency (SCID). This assay had the advantage of being quantitative, objective and highly reproducible in addition being able to detect atypical SCIDs and several other T-cell defects [14]. Implementing this newborn screening would be expected to facilitate early diagnosis of such disorders and prevent the long term disability seen secondary to late diagnosis.

These variable phenotypic presentations should alert all physicians who care for patients with recurrent infections that atypical presentations may occur when genes of the immune system are mutated. Extensive molecular work up are needed for patients with atypical presentations otherwise most of these conditions will go undetected, and the full spectrum of phenotypic and genotypic heterogeneity will not be known. One effective global tool for improving diagnosis of PIDs is increasing physician's awareness about these variable phenotypic presentations of PIDs. Continuing education of physicians from different specialties is important including those physicians who treat adolescents and adults. Along with disease-focused awareness campaigns, there is a need to support the development of appropriate diagnostic tools in these areas, including the use of immunological and molecular assays.

\section{References}

1. Al-Herz W, Aziz Bousfiha, Jean-Laurent Casanova, Helen Chapel, Mary Ellen Conley, et al. (2011) Primary immunodeficiency diseases: an update on the classification from the International Union of Immunological Societies Expert Committee for Primary Immunodeficiency. Front Immunol 2: 54

2. Schwarz K, Gauss GH, Ludwig L, Pannicke U, Li Z et al. (1996) RAG mutations in human B cell-negative SCID. Science 274: 97-99.

3. Villa A, Santagata S, Bozzi F, Giliani S, Frattini A, et al. (1998) Partial V(D)J recombination activity leads to Omenn syndrome. Cell 93: 885-896.

4. Corneo B, Moshous D, Güngör T, Wulffraat N, Philippet $P$, et al. (2001) Identica mutations in RAG1 or RAG2 genes leading to defective $V(D) J$ recombinase activity can cause either T-B-severe combined immune deficiency or Omenn syndrome. Blood 97: 2772-2776.

5. de Villartay JP, Lim A, Al-Mousa H, Dupont S, Déchanet-Merville J, et al. (2005) A novel immunodeficiency associated with hypomorphic RAG1 mutations and CMV infection. J Clin Invest 115: 3291-3299.

*Corresponding author: Hamoud Al-Mousa, Pediatric Allergy and Immunology Department of Pediatrics, King Faisal Specialist Hospital and Research Centre Riyadh, Saudi Arabia, Tel: 96614647272; Ext: 31987/ 27762; Fax: 96614427784 E-mail: hamoudalmousa@kfshrc.edu.sa

Received November 23, 2012; Accepted November 26, 2012; Published November 27, 2012

Citation: Al-Mousa H (2012) Variable Phenotypic Presentation of Primary Immunodeficiency Diseases: A Challenge for Diagnosis. J Blood Lymph 2:e111. doi:10.4172/2165-7831.1000e111

Copyright: (c) 2012 Al-Mousa $\mathrm{H}$. This is an open-access article distributed unde the terms of the Creative Commons Attribution License, which permits unrestricted use, distribution, and reproduction in any medium, provided the original author and source are credited. 
Citation: Al-Mousa H (2012) Variable Phenotypic Presentation of Primary Immunodeficiency Diseases: A Challenge for Diagnosis. J Blood Lymph 2:e111. doi:10.4172/2165-7831.1000e111

Page 2 of 2

6. Lindvall JM, Blomberg KE, Väliaho J, Vargas L, Heinonen JE, et al. (2005) Bruton's tyrosine kinase: cell biology, sequence conservation, mutation spectrum, siRNA modifications, and expression profiling. Immunol Rev 203: 200-215

7. Wood PM, Mayne A, Joyce H, Smith Cl, Granoff DM, et al. (2001) A mutation in Bruton's tyrosine kinase as a cause of selective anti-polysaccharide antibody deficiency. J Pediatr 139: 148-151.

8. Jin Y, Mazza C, Christie JR, Giliani S, Fiorini M, et al. (2004) Mutations of the Wiskott-Aldrich Syndrome Protein (WASP): hotspots, effect on transcription, and translation and phenotype/genotype correlation. Blood 104: 4010-4019.

9. Morra M, Silander O, Calpe S, Choi M, Oettgen H, et al. (2001) Alterations of the X-linked lymphoproliferative disease gene SH2D1A in common variable immunodeficiency syndrome. Blood 98: 1321-1325.

10. Arico M, Imashuku S, Clementi R, Hibi S, Teramura T, et al. (2001)
Hemophagocytic lymphohistiocytosis due to germline mutations in SH2D1A, the X-linked lymphoproliferative disease gene. Blood 97: 1131-1133.

11. Buckley RH (2004) Molecular defects in human severe combined immunodeficiency and approaches to immune reconstitution. Annu Rev Immunol 22: 625-655.

12. Ege M, Ma Y, Manfras B, Kalwak K, Lu H, et al. (2005) Omenn syndrome due to ARTEMIS mutations. Blood 105: 4179-4186.

13. Durandy A, Revy P, Fischer A (2004) Human models of inherited immunoglobulin class switch recombination and somatic hypermutation defects (hyper-IgM syndromes). Adv Immunol 82: 295-330.

14. Puck JM (2012) Laboratory technology for population-based screening for severe combined immunodeficiency in neonates: The winner is T-cell receptor excision circles. J Allergy Clin Immunol 129: 607-616. 